\title{
Grandparents and Stepgrandparents: Challenges in Counseling the Extended-Blended Family
}

\author{
Jane E. Myers \\ Valerie L. Schwiebert
}

Remarriage of parents may bring new grandparents and stepgrandparents into the lives of children, creating new family structures and needs for adjustment. The extended-blended family may benefit from specific counseling interventions.

Divorce and remarriage affect family structures in major ways that remain difficult to define (Aldous, 1995). Kinship relationships between members of blended families are developmental processes that change over time, and researchers have only recently begun to examine these relationships (Bray \& Berger, 1990). Divorces in first-time marriages, remarriages, and divorces after remarriage contribute to fluctuations in kinship networks for both adults and children. For example, remarriage of one or both parents may create as many as four new grandparents in the family system (Sanders \& Trygstad, 1989). These grandparents comprise part of both the extended family and the blended family and may be described as belonging to the extended-blended family.

Studies of relationships between grandparents and young grandchildren following divorce emphasize the importance of grandparents' roles in helping children adjust to single-parent and step-family life (Kennedy \& Kennedy, 1993). Role ambiguities in stepfamilies, however, contribute to difficulties in adjusting to new relationship patterns (Aldous, 1995). These ambiguities may be even more pronounced for stepgrandparents, who lack both biological ties and an extended history of relationships within the family (Sanders \& Trygstad, 1989). Counselors working with blended families find it useful to encourage relationships between children and grand-

Jane E. Myers is a professor in the Department of Counseling and Educational Development at The University of North Carolina, Greensboro. Valerie L. Schwiebert is an associate professor in the Department of Human Services and associate dean of graduate and research studies at Western Carolina University Culowhee, North Carolina. Correspondence regarding this article should be sent to Jane E. Myers, Department of Counseling and Educational Development, 222 Curry Building, 1000 Spring Garden Street, University of North Carolina, Greensboro,NC 27412 (e-mail: jemyers@uncg.edu). 
parents as well as stepgrandparents. To help children and grandparents relate effectively, counselors need to understand how, within the context of the nuclear family, they both benefit from various grandparenting roles and styles, and how parents mediate the grandparent-grandchild relationship. In this article we discuss various aspects of grandparent-grandchild relationships and stepgrandparenthood as a transition and life role that is both similar to and different from that of the biological grandparent in the family. Stages of adjustment to stepgrandparenthood are described, and implications for counselors are offered.

\section{GRANDPARENTHOOD AS A NORMATIVE LIFE TRANSITION}

It has been estimated that three fourths of people aged 65 and over are grandparents, and at least one half of these people will also become greatgrandparents (Hagestad \& Lang, 1986; Schwartz \& Waldrop, 1992). More children have living grandparents today than at any other time in history; there are approximately 48 living grandparents per 100 persons today, compared with 14 per 100 in 1900 . Schwartz and Waldrop (1992) estimated that one half of all grandparents are less than 60 years of age, and one third may be less than age 55. The greater number of grandparents is a reflection of longer lifespans, whereas their relative youth suggests that most grandparents will be in good health, financially stable, and independent (Aldous, 1995). Their reactions to becoming grandparents are known to vary by factors such as age, gender, life stage, life circumstances, and characteristics of the grandchild.

Younger grandparents may have a more difficult adjustment, because they may view the transition to grandparenthood as an "off-time" event. There is some evidence that "premature" grandparents (i.e., those in their 30s) may feel burdened and less willing to care for their grandchildren, whereas those who are very old may lack the energy to develop close relationships with young members of the family (Aldous, 1995). Although women are known to bond more closely than men with their grandchildren (Kivett, 1991), early grandmothers express discomfort with their roles when grandparenting interferes with other roles and relationships, such as parenting, employment, education, friendships, or romance (Hagestad \& Lang, 1986).

Persons who become grandparents during their 40 s and 50 s may bond quickly with grandchildren if generativity is an important psychological need (Myers \& Perrin, 1993), although these individuals may be busy with their own lives and careers and may not be readily accessible to their adult children or grandchildren. Older persons who have recently retired and are seeking new social roles may derive great pleasure from grandparenting experiences. 
The nature of the grandparent-grandchild relationship may be affected by the age of the child (Aldous, 1995). Older persons may find it easier to enjoy the companionship of infants and preadolescent children who have more time to spend with grandparents. Older children and adolescents are more likely to have developed peer relationships and thus are less likely to make time to build relationships with members of the older generation (Troll, 1983). The diversity of ages among both grandparents and grandchildren suggests the variety of roles and relationships that may develop within families.

\section{Grandparent Relationships, Roles, and Styles}

Hagestad and Lang (1986) found that "prospective grandparents do have definite ideas of what role behaviors are appropriate for a grandparent" (p. 119). For example, those who were becoming grandparents at an expected time were more likely to anticipate involvement in babysitting than those who were experiencing an off-time transition. Some of these role behaviors are socially defined and represent expectations for the grandparent role. Other behaviors of grandparents are influenced by the nature of the individual relationships with their grandchildren. The relationships of grandparents with their adult children affect the closeness of ties between grandparents and grandchildren as well (Kivett, 1991).

\section{Grandparent Roles and Styles}

The roles that grandparents play within a given family are highly variable and are based primarily on individual choice. Troll's (1983) early research revealed that grandparent roles are multidimensional in nature and not clearly defined. The roles that have been identified for grandparents include family historian, mentor, and storyteller. Grandparents are sometimes viewed as role models. Often, grandparents are perceived as people with the "right" to indulge grandchildren. Increasingly, grandparent roles are viewed as flexible and open to self-definition. Of course, these definitions may create conflicts within families, because parents or grandchildren may choose one or more roles for grandparents whereas grandparents themselves may have desires and preferences for other roles and relationships.

More recently, McAdoo and McWright (1994) considered grandparents to be central to family dynamics, because they serve both as family resources and as transmitters of family values. Denham and Smith (1989) suggested that grandparents have both indirect and direct influences on grandchildren, both of which are positive in nature. They may indirectly influence grandchildren in symbolic roles such as providers of a sense of roots and family history or that of family "watchdog." Grandparents directly and positively influence the development of grandchildren, whether 
they live with or apart from the children (Solomon \& Marx, 1995). Many grandparents are directly responsible for raising grandchildren (Jendrek, 1994; Solomon \& Marx, 1995); however, discussion of these situations is beyond the scope of the present article. Of more importance here is the impact of grandparents within the family, especially when parents divorce or when divorced parents remarry. It is at these times that the benefits of the grandparent relationship are most evident. Grandparents provide love and affection, care, shelter, company, closeness, trust, aid, and support (Kalliopuska, 1994).

\section{Grandparent-Grandchild Bonding}

Grandchildren benefit from relationships with grandparents affectively, cognitively, and materially. They also give much to the relationship, including joy, inspiration, love, tenderness, closeness, companionship, and hope for the future (Kalliopuska, 1994). Sanders and Trygstad (1993) found that most grandchildren consider their relationships with grandparents to be important.

Both the quality and quantity of contact affect the quality of grandparent-grandchild relationships. Cherlin and Furstenberg (1986) found that geographical distance accounted for $62 \%$ of the variance in frequency of contact, with those grandparents who lived in closest proximity having the most frequent contact. The age and health of the grandparent are important factors, with the youngest and healthiest grandparents more involved with and thus being perceived most positively by grandchildren (Sanders \& Trygstad, 1993; Whitbeck, Hoyt, \& Huck, 1993). Sanders and Trygstad (1993) also found that grandparents were perceived more positively by grandchildren in healthy or functional families.

The age of the grandchild is also a significant factor affecting the development of intergenerational bonds. Younger grandchildren perceive their relationships with grandparents as more supportive than do older children. (Cresey \& Kahiler, 1994). Grandchildren who share activities with grandparents report more positive relationships (Kennedy, 1992). Such activities may take place outdoors or in the community and include crafts, domestic helping, and entertainment. It is also common for parents to request and need more involvement and assistance from grandparents when children are younger.

\section{Parental Mediation of Grandparent-Grandchild Relationships}

One of the most important influences on the grandparent role is the extent to which it is mediated by the parents (Whitbeck et al., 1993). In fact, the grandparent role is unique in that it is created by choices made by someone else, not the grandparent him or herself. Adult children control whether or not one becomes a grandparent and when this transition occurs. They also 
control the amount of contact grandchildren have with grandparents. The quality of the relationship between parents and grandparents is central, in that parents have the power to set conditions and monitor the emotional context of the grandparent-grandchild relationship. The greater the closeness between parents and grandparents, the more likely there will be frequent contact and emotional closeness between grandchildren and grandparents (Cherlin \& Furstenberg, 1986; Kivett, 1991).

During times of family disruption, grandparents may play a vital role as stress buffers for their grandchildren (Denham \& Smith, 1989). When conflict exists within the nuclear family, grandparents may find themselves in a role best described as a double bind. Parents may expect them to be supportive while not interfering with either the parents' relationship difficulties or with childrearing activities (Thomas, 1990). The same relationship rules may apply when families separate or divorce, yet at these times potential roles for grandparents are likely to expand.

\section{Grandparenting and Divorce}

Numerous studies have shown that grandparents are more involved with grandchildren when parents divorce, suggesting that need is a strong motivator for intergenerational involvement (Denham \& Smith, 1989; Kennedy $\&$ Kennedy, 1993). Apparently, close romantic relationships between remarried spouses contribute to children and stepchildren's feelings of insecurity or noninclusion. As a consequence, the children may experience a greater need for closeness with grandparents and stepgrandparents.

Feelings of vulnerability may cause children to turn to grandparents for support, especially biological grandparents with whom relationships have already been established. Biological grandparents can provide a sense of stability during times of family disharmony and disruption. Children who experience a loss of family position in a new stepfamily may rely on the relationship with grandparents to mitigate the loss of power within the reconstituted family (Kennedy \& Kennedy, 1993).

After a divorce parents my restrict the access of biological grandparents to their grandchildren. They are thus unable to serve as resources even if they choose to do so. Paternal grandparents, in particular, may "feel 'left out' and 'forgotten' after the divorce, and frequently experience negative emotions and grief over the loss of their grandchildren" (Bray \& Berger, 1990, p. 419).

Knowing that divorce may result in restricted access to grandchildren or the severing of relationship ties by the custodial parent makes a divorce a significant and potentially traumatic event for grandparents. In examining custody and dispute cases referred to a family court clinic, Wilks and Melville (1990) found that two thirds of cases had some form of grandparent involvement. More than one third of the parents and three fourths of the 
children had lived in the grandparents' home during or after the parental separation. Virtually all states have passed grandparent visitation legislation (House Committee on Education and Labor, 1985); however, this legislation is specific to biological grandparents and not stepgrandparents.

\section{Stepgrandparenthood: A Challenge in Blended Families}

Bray and Berger (1990) noted that "remarriage and the formation of a stepfamily does not appear to be a static event, but the beginning of a process which requires integration of multiple family systems to facilitate children's adjustment" (p. 419). There is some evidence that perceptions of roles and role expectations on the part of all family members have an impact on the adjustment and integration of grandparents within the stepfamily (Henry, Celigan, \& Ostrander, 1993). Children learn how to relate to older family members through interactions with parents and grandparents. What they learn through these relationships becomes an unwritten "blueprint" that is lifelong, a lens through which they relate to others (Whitbeck et al., 1993). In blended families, different family members have different blueprints, different lenses. Expectations for how older family members will be treated may differ from members of the blended family. The role ambiguities that exist in stepfamilies will thus be even more significant for grandparents and stepgrandparents (Sanders \& Trygstad, 1989).

Relationships between stepgrandparents and stepgrandchildren will be affected by many factors, including the acceptance of the remarriage by the stepgrandparent and stepgrandchild, age of the child or children, frequency of visits, and needs and desires of all family members for support and inclusion (Sanders \& Trygstad, 1989; Trygstad \& Sanders, 1989). When an intact family separates, two sets of biological grandparents are affected. When families reconstitute through remarriage, the number of grandparent relationships increases significantly. A child whose parents divorce and both remarry may begin with four living grandparents, and suddenly have eight or more grandparents. If grandparents themselves divorce and remarry, the extended family constellation may become even more complex.

Parental mediation of children's time and emotional involvements may require restricted access to some or all sets of grandparents and stepgrandparents (Myers \& Perrin, 1993). This is especially so when grandparents and parents experience conflicted relationships and when grandparents fail to support parents in their relationship decisions. Even when parents choose to integrate grandparents and stepgrandparents into reconstituted families, the formation of emotional bonds between the generations must be viewed as a process with uncertain outcomes. Placing the development of emotional bonds within the context of normative developmental changes facilitates understanding of this process for family members. 


\section{The Transition to Stepgrandparenthood}

Henry et al. (1993) reviewed McGoldrick and Carter's (1982) discussion of developmental steps in the transition to remarried family life. Using the critical transition points for the reconstituted family, these authors presented a series of normative developmental issues in the transition to stepgrandparenthood. These issues revolve around the following central transition points: "ending the previous relationship; committing to the new relationship; announcing the decision to family and friends; and issues during remarriage, family formation, and as the realities of stepfamily life ensue" (p. 26). Henry et al. proposed four stages of adjustment to stepgrandparenting based on these transition points.

In the first stage, accepting the losses, all family members need to understand that stepfamilies emerge through loss, and losses require a process of grieving. Grandparents must accept the loss of their idealized image of a life-long happy marriage between their adult child and his or her spouse, and they must let go of their desire for a continued relationship between these two individuals. It is necessary that they accept the loss of traditional, biological grandparent roles.

The challenge of the second stage is to accept the adult child's single status. Grandparents at this time need to acknowledge the new ambiguity in family roles, adjust to the increased permeability of family boundaries, and accept the reorganization of the adult child's family. Increased contact with and support of both the adult child and grandchildren may be needed. At the same time, the tendency to assume parental roles of control within the family must be avoided.

Nonjudgmental acceptance of the adult child's choice of a new social network and new life partner is the challenge of the third stage of the transition to stepgrandparenthood. The major developmental tasks of this stage include acknowledging fears about the impact of the new relationship on existing family patterns and adapting to the adult child's new definition of family boundaries. Maintaining open communication at this time is essential. Grandparents must develop an historical perspective on the prior relationship that contributes to helping grandchildren experience a sense of their roots and at the same time avoid interfering with the new relationship. Acknowledging and preparing for potential stepgrandchildren is important, as well as developing an understanding of their relationship with the adult child and his or her potential spouse.

The final stage of transition is the establishment of new relationships within the context of the stepfamily. Family boundaries need to be redefined to include the new spouse and stepgrandchildren. Grandparents will need to develop realistic expectations for stepfamily living and clarify the expectations of the new marital dyad that affect grandparenting and stepgrandparenting roles. Grandparents should be aware of legal differences between relationships with 
grandchildren and relationships with stepgrandchildren and reevaluate their wills and inheritance plans (Aldous, 1995).

\section{IMPLICATIONS FOR COUNSELING}

Divorce, remarriage, family blending, and complex extended family networks have become commonplace in our society. At the same time, relationships between members of the extended-blended family have received little attention in the counseling literature. As a consequence, counselors may fail to realize or mobilize the resources of the extended-blended family in working with remarriage families. Challenges for counselors include at least five main components: helping families adjust to loss and change, helping families redefine their boundaries, helping members of the extended-blended family develop healthy and supportive relationships, providing information to assist families in recognizing and responding to available resources, and developing and implementing programs and interventions to facilitate the integration of grandparents and stepgrandparents within the reconstituted family.

\section{Helping Families Adjust to Loss and Change}

A review of the normative stages of adjustment to stepfamilies reveals that adjustment is a process that begins with a loss (Henry et al., 1993). Counselors can help all members of the family grieve their losses in preparation for acceptance and openness to new life experiences and relationships. All members of the family will need assistance in working through the unique aspects of their loss. Feelings about divorce, separation, and single parenting must be considered and clarified, and feelings of anger, resentment, sadness, or failure must be resolved. Family counseling literature often deals with losses experienced by the nuclear family. Attention to the needs of members of the extended family also is important. Addressing relationships between adult children and their parents can be an important first step in the transition to healthy family blending when parents remarry.

\section{Helping Blended Families Redefine Their Boundaries}

There is adequate research support for the potential importance of grandparents and stepgrandparents within family systems to justify a focus on the older generation when working with reconstituted families.

Grandparents and stepgrandparents can be valuable resources for meeting children's' emotional needs while the new spousal dyad begins to develop strong relationship bonds. Having their needs met through relationships with grandparents and stepgrandparents may prevent children from being disruptive or using power strategies to keep the spousal dyad in turmoil during the early stages of the new marriage. Grandparents 
will need to provide a strong support system for grandchildren who fear the loss of power or position in the new family structure or who experience conflicts of loyalty as the stepfamily forms. However, geographic limitations, anger towards the divorced or separated parents, and taking sides in the divorce can be issues that interfere with willingness of the grandparents or other family members to seek counseling.

\section{Helping Members of the Extended Blended Family Develop Healthy Relationships}

It cannot be assumed that healthy relationships (or any relationships) will develop in the extended-blended family (or any other blended family component). Counselors can assist members of the family in defining roles and expectations, clarifying needs and wants, and being assertive in getting their needs met in an appropriate manner. Counselors can help families understand the importance of establishing relationships between stepgrandparents and grandchildren, especially when the children are young. A systems approach that involves all members of the family may have the most potential for success, especially because parents will be mediators of any relationships between members of the extended-blended family (Trygstad \& Sanders, 1989).

Grandparents also will need to establish new relationships with the adult child's former spouse and support contact of the grandchildren with the former spouse. They may find it necessary to adjust to the meaning of new knowledge about their child's dissatisfaction with the former spouse, even if they personally experienced positive relationships with the former spouse.

Establishing appropriate and satisfying terminology for referring to persons in the extended-blended family will also be important. The sharing of information and experiences and development of new emotional attachments will occur gradually over time as these developmental challenges are addressed.

\section{Providing Information to Assist Families in Responding to Resources}

Sanders and Trygstad (1989) emphasized the need for counselors to provide accurate and timely information for families to assist them in making relationship decisions. This information would include consideration of the variety of possible roles for grandparents and stepgrandparents and the need to explore, clarify, and develop consistent expectations for these roles within the extended-blended family. Grandparents and stepgrandparents should be included in family therapy, because the potential for positive as well as negative influences within the family are so well documented. By developing stronger relationships between grandchildren and grandparents, other relationships in the family may be strengthened, including those between the adult child and his or her parents as well as the adult children and their own children. 


\section{Developing and Implementing Programs and Interventions}

Strom and Strom (1993) suggested that grandparents should have access to a structured psychoeducational intervention that would help them adjust to their changing roles and relationships. By helping grandparents adjust to family changes, these individuals can become even more important resources for other members of the family. Counselors may find grandparenting assessment tools useful in designing psychoeducational interventions. For example, the Grandparent Strengths and Needs Inventory (Collinsworth, Strom, Strom, \& Young, 1991) can serve as an assessment tool to help identify the strengths of individual grandparents and help to individualize the training program to meet their unique needs. This inventory assesses six dimensions of grandparenting roles (satisfaction, success, teaching, difficulty, frustration, and information needs) for which both group and individual interventions could be structured.

The development and field testing of model programs for counseling extended-blended families is needed. The identification of effective interventions and systematic approaches to working with these families would benefit practitioners in family-life education and counseling settings. Until such programs have been developed, counselors may find themselves being most helpful to remarriage families by including the extended-blended family in the definition of the family network.

\section{REFERENCES}

Aldous, J. (1995). New views of grandparents in intergenerational context. Journal of Family Issues, 16, 104-122.

Bray, J. H., \& Berger, S. H. (1990). Noncustodial father and paternal grandparent relationships in stepfamilies. Family Relations, 32, 414-419.

Cherlin, A., \& Furstenberg, F. (1986). The new American grandparent: A place in the family, a life apart. New York: Basic Books.

Collinsworth, P., Strom, R., Strom, S., \& Young, D. (1991). The Grandparent Strengths and Needs Inventory: Development and factorial validation. Educational and Psychological Measurement, 51, 785-792.

Cresey, G. L., \& Kahiler, G. (1994). Age differences in grandchildren's perceptions of relations with grandparents. Journal of Adolescence, 17, 411-426.

Denham, T. E., \& Smith, C. W. (1989). The influence of grandparents on grandchildren: A review of the literature and resources. Family Relations, $38,345-350$.

Hagestad, G. O., \& Lang, M. E. (1986). The transition to grandparenthood. Journal of Family Issues, 7, 115-130.

Henry, C. S., Celigan, C. P., \& Ostrander, D. L. (1993). The transition to stepgrandparenthood. Journal of Divorce and Remarriage, 190, 25-44. 
House Committee on Education and Labor. (1985). Grandparent rights. Washington, DC: House of Representatives, Ninety-Ninth Congress. Jendrek, M. P. (1994). Grandparents who parent their grandchildren. The Gerontologist, 34, 206-216.

Kalliopuska, M. (1994). Relations of retired people and their grandchildren. Psychological Reports, 75, 1083-1088.

Kennedy, G. E. (1992). Shared activities of grandparents and grandchildren. Psychological Reports, 70, 211-227.

Kennedy, G. E., \& Kennedy, C. E. (1993). Grandparents: A special resource for children in stepfamilies. Journal of Divorce and Remarriage, 19, 45-68.

Kivett, V. (1991). The grandparent-grandchild connection. Marriage and Family Review, 16, 267-290.

McAdoo, H. P., \& McWright, L. A. (1994). The roles of grandparents: The use of proverbs in value transmission. Activities, Adaptation. and Aging, 19, 27-38.

McGoldrick, M., \& Carter, E. A. (1982). The family life cycle. In F. Walsh (Ed.), Normal family processes (pp. 67-195). New York: Guilford Press. Myers, J. E., \& Perrin, N. (1993). Grandparents affected by parental divorce: A population at risk? Journal of Counseling \& Development, 72, 62-72.

Sanders, G. F., \& Trygstad, D. W. (1989). Stepgrandparents and grandparents: The view from young adults. Family Relations, 38, 71-75.

Sanders, G. F., \& Trygstad, D. W. (1993). Strengths in the grandparentgrandchild relationship. Activities, Adaptation, and Aging, 17, 43-53.

Schwartz, J., \& Waldrop, J. (1992). The growing importance of grandparents. American Demographics, 14, 10-11.

Solomon, J. C., \& Marx, J. (1995). "To grandmothers' house we go": Health and school adjustment of children raised solely by grandparents. The Gerontologist, 35, 386-394.

Strom, R., \& Strom, S. (1993). Grandparent development and influence. Journal of Gerontological Social Work, 20, 3-16.

Thomas, J. (1990). The grandparent role: A double bind. International Journal of Aging and Human Development, 31, 169-177.

Troll, L. (1983). Grandparents and the family watchdog. In T. H. Brubaker (Ed.), Family relationships in later life (pp. 63-74). Beverly Hills, CA: Sage.

Trygstad, D. W., \& Sanders, G. F. (1989). The significance of stepgrandparents. International Journal of Aging and Human Development, 29, 119-134.

Whitbeck, L. B., Hoyt, D. R., \& Huck, S. M. (1993). Family relationship history, contemporary parent-grandparent relationship quality, and the grandparent-grandchild relationship. Journal of Marriage and the Family, 55, 1025-1035.

Wilks, C., \& Melville, C. (1990). Grandparents in custody and access disputes. Journal of Divorce, 13, 1-14. 